\title{
Correlation of Occipito-Frontal Circumference and Occipito-Heel Length with Birth Weight of Singleton Term Babies in Enugu, South East, Nigeria
}

\author{
Ozor Ignatius Ikemefuna ${ }^{1,2, ~ *, ~ N d u a g u b a m ~ O b i n n a ~ C h w u k w u e b u k a ~}{ }^{3}$, Okafor Igwebuike Innocent ${ }^{4}$, \\ Agwagu Zita Njideka ${ }^{5}$, Abireh Ifeanacho Ezeteonu ${ }^{1}$, Ozioko Sebastine Uche ${ }^{1}$, \\ Ugwuanyi Obinna Kingsley ${ }^{1}$ \\ ${ }^{1}$ Department of Anatomy, College of Medicine, Enugu State University of Science and Technology, Enugu, Nigeria \\ ${ }^{2}$ Department of Surgery, College of Medicine, Enugu State University of Science and Technology, Enugu, Nigeria \\ ${ }^{3}$ Department of Paediatrics, Enugu State University Teaching Hospital, Enugu, Nigeria \\ ${ }^{4}$ Department of Obstetrics and Gynaecology, Enugu State University Teaching Hospital, Enugu, Nigeria \\ ${ }^{5}$ Nursing Unit, Enugu State University Teaching Hospital, Enugu, Nigeria
}

Email address:

ikemozor@yahoo.com (Ozor I. I.)

${ }^{*}$ Corresponding author

\section{To cite this article:}

Ozor Ignatius Ikemefuna, Nduagubam Obinna Chwukwuebuka, Okafor Igwebuike Innocent, Agwagu Zita Njideka, Abireh Ifeanacho Ezeteonu, Ozioko Sebastine Uche, Ugwuanyi Obinna Kingsley. Correlation of Occipito-Frontal Circumference and Occipito-Heel Length with Birth Weight of Singleton Term Babies in Enugu, South East, Nigeria. American Journal of Pediatrics. Vol. 6, No. 4, 2020 , pp. $463-467$. doi: 10.11648/j.ajp.20200604.23

Received: August 4, 2020; Accepted: August 18, 2020; Published: November 19, 2020

\begin{abstract}
Background: Anthropometric measurements of the new-borns are important indicators of their intra-uterine growth and development; and could be reliable predictors of their health status. This study was carried out to determine the relationships between occipito-frontal head circumference and occipito-heel length to the birth weight of singleton term newborns in ESUTH, Enugu. Methods: A total of 1000 (500 males and 500 females) live singleton term babies whose mothers gave consent for participation and satisfied the inclusion criteria were consecutively recruited from the labour ward of ESUTH, Enugu from June 1, 2015 to May 31, 2017. The birth weight (BW), occipito-frontal circumference (OFC) and occipito-heel length (OHL) of the new-borns were measured and documented. The weight and OHL of the new-borns were used to calculate the babies' body mass index (BMI). Data obtained was entered into SPSS version 20 and then analysed. Results: The mean values of their $\mathrm{OFC}$, OHL and $\mathrm{BW}$ were $34.6 \pm 2.2 \mathrm{~cm} ; 49.8 \pm 3.0 \mathrm{~cm}$ and $3.3 \pm 1.4 \mathrm{~kg}$ respectively. There was a significant difference between the OFC $(\mathrm{p}=0.012)$ and OHL $(\mathrm{P}=0.035)$ but not in $\mathrm{BW}(\mathrm{P}=0.220)$ and $\mathrm{BMI}(\mathrm{p}=0.446)$ in males neonates compared to females. A significant correlation (Pearson's) of OFC $(\mathrm{r}=0.149 ; \mathrm{P}=0.000)$ and $\mathrm{OHL}(\mathrm{r}=0.145 ; \mathrm{p}=0.000)$ with birth weight was also found. There was also a significant correlation of OFC $(r=0.106 ; \mathrm{P}=0.001)$ and OHL $(\mathrm{r}=-0.156 ; \mathrm{p}=0.000)$ with BMI. Conclusion: The birth weight and BMI of new-born babies are good determinants of their OFC and OHL.
\end{abstract}

Keywords: Term Newborn, OFC, OHL BMI, Correlation

\section{Introduction}

The occipito-frontal circumference (OFC) of the new-born is a reliable predictor of the volume of the brain tissue and thus the health status of the new-born [1]. The OFC is the largest circumference of the head of the newborn at birth [2] and is measured in centimetre $(\mathrm{cm})$ with a tape placed above the ears and midway between the eyebrows and the hairline to the occipital prominence at the back of the head [3].

Measuring OFC is a quick, non-invasive method of determining the head size and subsequently diagnosis of micro- or macro-cephaly [4]. Anthropometric measurements 
are important because some neonatal characteristics such as birth weight, Ponderal index, occipito-heel Length (OHL), OFC and Apgar score are used as proxies for the quality of care during the perinatal period and at childbirth. They may also be associated with the risk of developing various diseases such as macro-cephaly with possible hydrocephalus, respiratory distress syndrome as well as type II diabetes and cardiovascular diseases in later life [5].

Anthropometric parameters apart from providing standards also serve as useful adjuncts to other observations in evaluating intrauterine growth and development as well as in detecting neonatal health problems. Results from such measurements are used in various fields of medical practices especially in Paediatrics, and Neurosurgery to compare variations between patients and normal populations [6]. Anthropometric studies are also used to obtain the characteristics of ethnic groups inhabiting a particular geographical region. It is also useful in understanding the frequency distribution of human morphologies and in providing the basis for a comparison among different races $[7$, $1,8]$

OHL is another important anthropometric assessment that determines the actual length of the new-born at birth. It is the measurement taken from the occiput of the head to the heel of the new-born's foot. It is measured in centimetres. The average length of full term babies at birth is $51 \mathrm{~cm}(46-56 \mathrm{~cm})$. OHL may have correlations with the OFC and birth weight.

The birth weight (BW) is a critical determinant of survival, growth and development of the new-born and also a valuable indicator of maternal health, nutrition and quality of antenatal services $[8,9]$. It is also known that a significant relationship exists between birth weight and neonatal complications, mortality and developmental delay $[9,10]$.

This study was carried out to determine the co-relations of OFC and OHL with BW of singleton term babies in ESUTH, Enugu, South-East Nigeria.

\section{Materials and Methods}

The study was a prospective cohort study involving 1000 booked term singleton Igbo new-borns (500 males and 500 females) born at gestational ages of 37-42 weeks and whose mother's age were between 20-40 years. The Study was explained to their mothers following which a consent form was filled by their mothers who accepted to participate in the study. The mothers were interviewed and their sociodemographic data was ascertained and entered into the proforma designed for the study. The newborn was then physically examined to ensure he/she has no obvious birth anomaly.

\subsection{Inclusion Criteria}

1. New-borns who are products of booked singleton pregnancies and who have no obvious birth anomaly.

2. Term new-borns (born at gestational age between 37 42 weeks).

\subsection{Study Population}

A total of 1000 apparently healthy booked singleton term Igbo newborns (500 males and 500 females) who satisfied the inclusion criteria were enrolled into the study.

\subsection{Study Site and Duration}

The study was carried out in the labour ward of the Enugu State University Teaching Hospital (ESUTH) Parklane in Enugu State South-East, Nigeria over a 2 year period (June 2015 to May 2017).

\subsection{At the Labour Wards}

All new-born babies whose mother gave consent for participation and satisfied the inclusion criteria were enrolled into the study. After obtaining the mother's sociodemographic details including her age, gestational age at delivery, mode of delivery; gravidity and parity were ascertained from her hospital records and were recorded into the proforma designed for the study. The child anthropometric measurements of birth weight (BW), Occipito-Heel Length (OHL) and OFC were measured as shown in Figures 1 to 3 . The birth weight of the newborns was measured without any undergarment using an electronic scale and the weight is ascertained to the nearest $0.01 \mathrm{~kg}$. The new-born is again repositioned on the weighing scale and the weight measure is repeated. The two measures were then compared to know if they were within $0.1 \mathrm{~kg}$ tolerance limit. New-borns whose weight measures exceeded the tolerance limit were again repositioned and a third time. The average of the two measures in closest agreement was then taken and was recorded.

The OHL was measured using a flexible non- stretchable measuring tape to the nearest $0.1 \mathrm{~cm}$. It was from the occiput to the heel of the foot. The tape was again repositioned and the OHL was re-measured. The OHL measures should agree within $0.2 \mathrm{~cm}$ tolerance limit. If the difference between measures exceeds the tolerance limit, the new-born was repositioned and re-measured a third time. The average of the two measures in closest agreement was then taken and was recorded on the proforma.

The OFC was measured using a flexible non-stretchable measuring tape. The tape is placed over the most prominent part of the back of the head (occiput) and in front of the head just above the eyebrows (supraorbital ridge/ glabella). The tape is pulled snugly to compress the hair and to fit firmly on the skin. The measurement was read to the nearest $0.1 \mathrm{~cm}$. The tape is again repositioned and the OFC re-measured. The OFC measures should agree within $0.2 \mathrm{~cm}$ tolerance limit. If the difference between measures exceeds the tolerance limit, the new-born was repositioned and re-measured a third time. The average of the two measures in closest agreement was then taken and was recorded on the proforma.

The Weight and OHL of new-born was used to calculate the Body Mass index using the formula: Weight in $\mathrm{Kg} / \mathrm{Height}$ in $\mathrm{m}^{2}$. 


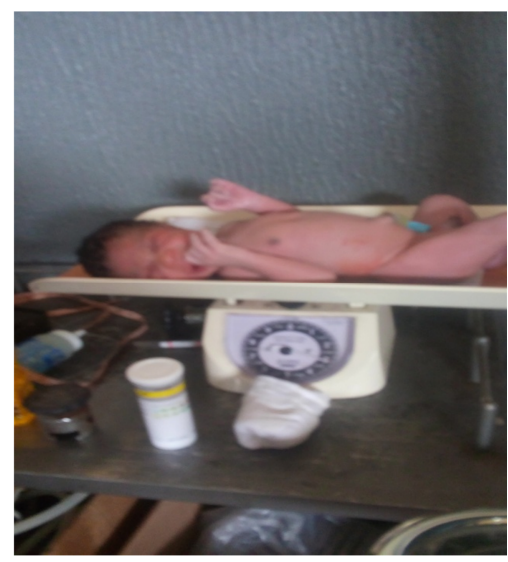

Figure 1. Measurement of the weight of the new-born.

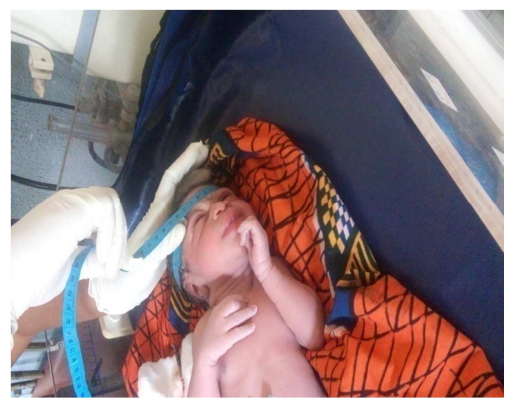

Figure 2. Measurement of the OFC of the newborn.

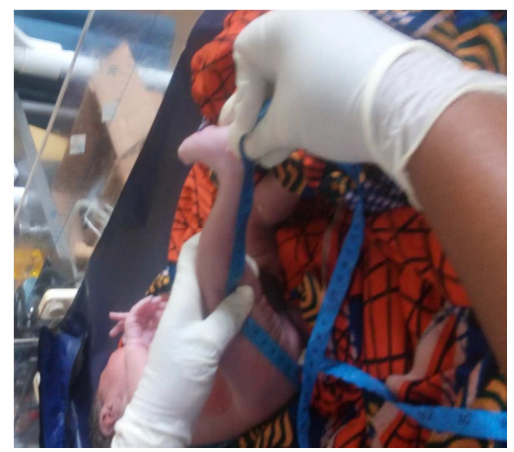

Figure 3. Measurement the OHL of the newborn.

\subsection{Data Analysis}

Data obtained was then entered into the appropriate sections of the proforma and subsequently transferred into SPSS version 20. Data was analysed using inferential statistics and linear regression. Comparison of means was done using the independent t-test. The level of statistical significance was set at 0.05 .

\section{Results}

In this study of full term new-borns of Igbo extraction, a total of 1,000 new-borns were recruited into the study. The mean values of their OFC, OHL and BW were $34.6 \pm 2.2 \mathrm{~cm}$; $49.8 \pm 3.0 \mathrm{~cm}$ and $3.3 \pm 1.4 \mathrm{~kg}$ respectively.

There was a significant difference between the OFC $(\mathrm{p}=0.012)$ and OHL $(\mathrm{P}=0.035)$ in males compared to female neonates. However there was no difference between the BW $(\mathrm{P}=0.220)$ and $\mathrm{BMI}(\mathrm{p}=0.446)$ in males neonates compared to females.

Table 1 show that there was a significant association (Pearson's correlation) between Birth Weight and OFC as well as between Birth weight and OHL.

Table 1. Association between OFC, OHL and Birth weight.

\begin{tabular}{lll}
\hline Birth weight & R & Sig (2-tailed) \\
\hline OFC & 0.149 & 0.000 \\
OHL & 0.145 & 0.000 \\
\hline
\end{tabular}

The degree of prediction of birth weight by OFC and OHL were $2.2 \%$ and $2.1 \%$ respectively.

Table 2. Regression analysis for prediction of Birth weight by OFC and OHL.

\begin{tabular}{lll}
\hline Birth weight & $\mathbf{R}$ & $\mathbf{R}^{\mathbf{2}}$ \\
\hline OFC & 0.149 & 0.022 \\
OHL & 0.145 & 0.021 \\
\hline
\end{tabular}

There was also a significant association between BMI and OFC $(\mathrm{r}=0.106 ; \mathrm{P}=0.001)$ and between BMI and OHL $(\mathrm{r}=-$ $0.156 ; \mathrm{p}=0.000)$. The degree of prediction of $\mathrm{OFC}$ and $\mathrm{OHL}$ by BMI are $1.1 \%$ and $2.4 \%$ respectively.

A significant correlation (Pearson's) was found between mother's age and the OFC of their babies $(r=0.082 ; \mathrm{p}=0.010)$ but not with their OHL $(\mathrm{r}=-0.017 ; \mathrm{p}=0.597)$ and birth weight $(\mathrm{r}=-0.028, \mathrm{p}=0.377)$.

There was a significant relationship between gestational age at delivery and OHL $(r=0.082 ; \mathrm{p}=0.009)$ but not with OFC $(\mathrm{r}=0.050 ; \mathrm{P}=0.114)$ and Birth weight $(\mathrm{r}=0.019$; $\mathrm{p}=0.547)$.

Table 3. Comparison between $O F C, O H L, B W$.

\begin{tabular}{|c|c|c|c|}
\hline Authors & Work & Ethnic group & Observation (Mean Values) \\
\hline \multirow{3}{*}{ Kaur et al (2013) [11] } & $\mathrm{OFC}$ & \multirow{3}{*}{ Faridkot, Punjab } & $\mathrm{OFC}=32.5 \pm 2.2$ \\
\hline & OHL & & $\mathrm{OHL}=46.1 \pm 3.3$ \\
\hline & BW & & $\mathrm{BW}=2.39 \pm 3.3$ \\
\hline \multirow{3}{*}{ Kataria SK and Gaur S (2014) [12] } & $\mathrm{OFC}$ & \multirow{3}{*}{ Jodhpur, Rajasthan } & $\mathrm{OFC}=36.55 \pm 1.19$ \\
\hline & OHL & & $\mathrm{OHL}=47.95 \pm 10$ \\
\hline & BW & & $\mathrm{BW}=2.92 \pm 0.39$ \\
\hline \multirow{2}{*}{ Taksande et al (2008)[13] } & $\mathrm{OFC}$ & \multirow{2}{*}{ Maharashtra, India } & $\mathrm{OFC}=33.52 \pm 1.92$ \\
\hline & BW & & $\mathrm{BW}=2.82 \pm 0.28$ \\
\hline \multirow{3}{*}{ Anupama MP and Dakshayani KR (2003) [14] } & $\mathrm{OFC}$ & \multirow{3}{*}{ Mysore } & $\mathrm{OFC}=32.60 \pm 2.52$ \\
\hline & OHL & & $\mathrm{OHL}=46.6 \pm 3.36$ \\
\hline & BW & & $\mathrm{BW}=\ldots \ldots$ \\
\hline Suneetha B and Kavitha VK (2016) [15] & $\mathrm{OFC}$ & Hyderabad & $\mathrm{OFC}=32.72 \pm 1.72$ \\
\hline
\end{tabular}




\begin{tabular}{llll}
\hline Authors & Work & Ethnic group & Observation (Mean Values) \\
\hline & OHL & & OHL $=47.28 \pm 4.17$ \\
& BW & & BW $=2.64 \pm 0.49$ \\
& OFC & OFC $=33.58 \pm 1.17$ \\
Soni P and Kapoor K (2017) [8] & OHL & Himachal Pradesh & OHL $=48.71 \pm 3.82$ \\
& BW & & BW $=2.91 \pm 0.41$ \\
Present study (2020) & OFC & OFC $=34.6 \pm 2.2$ \\
& OHL & Igbo, Enugu, Nigeria & OHL $=49.8 \pm 3.0$ \\
\hline
\end{tabular}

$\mathrm{OFC}=$ Occipito frontal Circumference $(\mathrm{cm})$.

$\mathrm{OHL}=$ Occipito-Heel Length $(\mathrm{cm})$.

$\mathrm{BW}=$ Birthweight $(\mathrm{kg})$.

\section{Discussion}

The size of newborn at birth has been acknowledged as a significant indicator of both fetal and neonatal health. However, size at birth reflects both the duration of gestation and rate of fetal growth [8]. It must therefore be considered with respect to gestational age [16]. There is death of literature of studies correlating OFC with OHL and BW in newborns in Nigeria especially in Enugu, South East.

Our present studies revealed OFC to be $34.6 \pm 2.2 \mathrm{~cm}$. This is in keeping with several studies (Table 3), which estimated OFC to be between $32-36 \mathrm{~cm}$ [8]. Similar result was obtained by Soni and Kapoor (2017) in their works done which OFC of New borns in Himachal Pradesh was estimated to be $33.58 \pm 1.17 \mathrm{~cm}$ [8].

OHL obtained in our study $(49.8+3.0)$ is similar to the findings see in similar studies done as contained in table 3 . However, the slight differences seen can be attributed to racial, ethnic and environmental factors among other possible factors.

The birth weight found in this present study is $3.3 \pm 1.4 \mathrm{~kg}$. This is though similar to the findings in similar studies. However, the birth weight is higher in our present study compared to what is seen in previous works. The difference in the birth weight may be due to ethnic, genetic, racial or environmental factors.

In this study of the correlation of OFC and OHL with BW of singleton term Igbo babies in South East Nigeria, a significant difference was found between OFC and OHL in normal male babies compared to females. This collaborates with the findings in an earlier work Erica et al., 2011 [10] which showed a significant difference between OFC and OHL [17].

There was also no significant difference between weight and BMI in males compared to female babies. This however disagrees with the findings in the work by [17] which revealed that head circumference correlates with height, weight and BMI. Differences in methodology and in the settings in which these studies were conducted may be responsible for the variance in findings.

There was a significant association between birth weight and OFC as well as between birth weight and OHL. The study revealed that the higher the birth weight of the term baby; the higher the baby's OFC and OHL at birth. These findings are consistent with the work of Jenni [18] which suggested that size at birth is not only an important determinant of the baby's OFC and OHL but also an important determinant of birth outcomes and mortality rate. By extrapolation, it may well mean that in noting the size of the head or OFC of a newborn and using it in making a possible diagnosis such as in hydrocephalus or microcephaly especially when other causative factors are not glaring, the weight of the baby at birth will be put into cognizance. However; [19] in their study noted that neonatal body measurements vary in their association with birth weight. Differences in study design and sample sizes may be have contributed to the differences in findings.

The study showed near equal degree of prediction of birth weight by OFC and OHL which means that they have near equal statistical association with birth weight. However, the degree of prediction of OFC and OHL by BMI was found to be $1.1 \%$ and $2.4 \%$ respectively which probably means that BMI is a better predictor of OHL than OFC. This finding supports the work by [20] which reported that BMI is a strong predictor of OHL. This could probably be connected with the fact that height/length is a component of the formula for calculating BMI which OFC is not.

In this study there was also a significant relationship between maternal age and OFC of the new-borns but not with OHL or Birth weight. The reason for this is unclear and further studies are needed to clarify this.

\section{Conclusion}

The birth weight and BMI of new-born babies are good determinants of their OFC and OHL.

The birth weight and BMI of new born babies are good determinants of their OFC and OHL. The values of OFC, OHL and BW vary slightly among racial, ethnic and environmental boundaries. The values obtained in our study can be used as a normative value for new born babies in Enugu, South East, Nigeria.

\section{Recommendation}

Further studies with larger sample sizes are needed to fully elucidate these relationships. 


\section{References}

[1] Everekloglu C, Doganary SE, Gunduz A, Terca M, Balat A, and Cumurcu T. (2002). Craniofacial Antropometry in a Turkish population. Cleft palate Craniofac. J., 39: 208-218.

[2] Golalipour MJK., Haidari M., Jahanshahi MA and Farahani RM. (2003). The shapes of head and face in normal male newborns in South East of Caspian sea (Iran-Gorgan). J. Anat. Soc. India, 52: 28-31.

[3] Golalipour MJ, Heidarai M., Jahanshahi MA., Vakilli and Mohareri AR. (2001). Relationship between race and head surface variation in newborn girls in GorganUnit. MedSci. J. 8: 47-52.

[4] Holden KR. (2014). Heads you win, tails you lose: measuring head circumference. Dev. Med. Child Neurol: 56 (8): 705.[PubMed][Google Scholar].

[5] Heidari Z., Sagheb HRM? Mohammadi M. Moogchi SMHN and Arab A. (2004). Cephalic and prosopic indices: Comparison in one-day newborn boys in Zahedan. Tehran Univ. Med. J. 62: 156-165.

[6] Zaidi SH. (1989). Antropological study of the mastoid air cell system in Pakistani races. J. Laryngol. Otal., 103: 819-822.

[7] Golalipour MJ., Jahanshahi M and Haidari K. (2005). The Variation of head and face shapes in female newborns in the South-East of the Caspian Sea. (Iran-Gorgan). Eur. J. Anat., 9: 95-98.

[8] Soni P and Kapoor K. (2017). Correlation of Birth Weight with other Anthropometric Parameters of Newborns in Himachal Pradesh. Int J. Cur. Res. Rev. Vol 9, Issue 15, doi: 10.7324/IJCRR.2017.9159.

[9] Ezenwosu OA, Ndu IK, Ekwochi U, Osuorah DC, Amadi OF, Nwokoye IC and Odetunde OI. (2014). Out-of-pocket cost managing sick newborns in Enugu, Southeast, Nigeria. CliniEconomics and outcomes research: CEOR, 6: 29-35. https:/doi.org/10.2147/CEOR. S54674.

[10] Fatemeh T, Sedigheh AA, Saba A, Farin S \& Hamid AM. (2012). Correlation between high-risk pregnancy and developmental delay in children aged 4-60 months, Libyan Journal of Medicine, 7: 1, 18811, doi: 10.3402/ijm.v7i0.18811.

[11] Kaur M, Singh Z, Kaur G and Goyal LD. (2013). Correlation of birth weight with other anthropometric measurements of newborns. Indian Journal of Basic \& Applied Medical Research; 8 (2): 870-79.

[12] Kataria SK and Gaur S. (2014). An Anthropometric Study of Normal Full Term Newborns at Birth in Western Rajasthan. International Journal of Advanced Research; 2 (10): 671-75.

[13] Taksande AM, Lakhkar B and Gadekar A. (2015). Anthropometric measurements of term neonates in tertiary care hospital of Wardha district. Al Ameen J Med Sci; 8 (2): 140-43.

[14] Anupama MP and Dakshayani KR. (2013). The study of Anthropometric Measurements of Newborn Babies in Relation to Maternal Illness. Anatomica Karnataka.; 7 (1): 67 71.

[15] Suneetha B and Kavitha VK. (2016). A study of relationship between birth weight and various anthropometric parameters in neonates. IOSR Journal of dental and medical sciences. Feb; 15 (2): 50-57.

[16] Kramer JK, Farnworth ER, Johnston KM, Wolynetz MS, Modler HW and Sauer FD. (1990). Myocardial changes in newborn piglets fed sow milk or milk replacer diets containing different levels of erucic acid. Lipids; 25 (11): 729-37.

[17] Erica JG, Paula VD, Janina C, Remco V, Michael BR, Stef VB, Jan MW and Wilma O. (2011). Association between Head Circumference and Body Size. Horn. Res. Paediatr: 75: 213219. doi: $10.1159 / 000321192$.

[18] Jenni Vaarno. (2014). Length and Head Circumference at Birth: Association with Birth Outcome and Morbidity in Macrosomic Finnish Infants. Master's thesis, 65 pages. University of Eastern Finland, Faculty of Health Sciences, Public Health Nutrition.

[19] Pomeroy E, Stock JT, Cole TJ, O'Callaghan M, Wells JCK. (2014). Relationships between Neonatal Weight, Limb Lengths, Skinfold Thicknesses, Body Breadths and Circumferences in Australian Cohort. PLos ONE 9 (8): e105108. doi: 10.1371/journl.pone.0105108.

[20] Lofgren I, Herron K, Zern T, West K, Patalay M, Shachter NS, Koo SI, \& Fernandez ML. (2004). Waist circumference is a better predictor than body mass index of coronary heart disease risk in overweight premenopausal women. The journal $\begin{array}{llll}\text { of nutrition, } 134 & \text { (5), } & 1071-1076 .\end{array}$ https:/doi.org/10.1093/ijn/134.5.1071. 